\title{
Compreensão dos Graduandos dos Cursos de Ciências Contábeis Quanto aos Conceitos Relevantes Ensinados na Disciplina de Teoria da Contabilidade em IES da Grande Florianópolis
}

\begin{abstract}
Resumo
Esta pesquisa tem como objetivo identificar a compreensão dos graduandos do curso de Ciências Contábeis quanto aos conceitos relevantes ensinados na disciplina de Teoria da Contabilidade. Para o atingimento desse objetivo foi elaborado um questionário enviado a instituições selecionadas ou aplicado presencialmente, obtendo um total de 65 respondentes que já haviam cursado a disciplina de Teoria da Contabilidade. Os resultados dessa pesquisa mostram que os alunos percebem os conceitos relacionados à disciplina de forma mais ligada à normatização e que, pela maior parte dos respondentes, a disciplina Teoria da Contabilidade foi considerada de fundamental importância, não devendo ser eliminada. Além disso, não se pode afirmar que exista relação entre a área e o tempo de atuação dos respondentes com as suas percepções relativas aos conceitos da disciplina. Observou-se ainda que há pouca discussão sobre alguns temas, em que alguns alunos os desconhecem totalmente, como no caso da Teoria da Agência e de Earnings Management, o que pode indicar um gap quanto ao ensino da disciplina. Para futuras pesquisas sugere-se analisar o ensino a distância e pesquisas que busquem analisar a existência desse possível gap observado.
\end{abstract}

Palavras-chave: Teoria da Contabilidade. Ensino de Contabilidade. Conceitos Relevantes.

\section{Fabiana Frigo Souza}

Mestranda em Contabilidade pela Universidade Federal de Santa Catarina (UFSC)Endereço: Departamento de Ciências Contábeis, Campus Universitário Reitor João David Ferreira Lima, Universidade Federal de Santa Catarina, Trindade, Florianópolis-SC, CEP: 88.040-900 E-mail: fabiiana_fs@hotmail.com

\section{Ernesto Fernando Rodrigues} Vicente

Doutor em Administração pela Universidade de São Paulo (USP) Professor da Universidade Federal de Santa Catarina (UFSC)Endereço: Departamento de Ciências Contábeis, Campus Universitário Reitor João David Ferreira Lima, Universidade Federal de Santa Catarina, Trindade, Florianópolis-SC, CEP: 88.040-900

E-mail: ernesto.vicente@ufsc.br 


\section{Introdução}

A disciplina Teoria da Contabilidade passou a ser obrigatória para os cursos de Ciências Contábeis a partir da Resolução 03, de 1992, do Conselho Federal de Educação (CFE) (Ferreira, Splitter \& Borba, 2012). A partir de então, passou a ter maior representatividade e, segundo Madeira, Mendonça e Abreu (2003, p. 104), a ser "reconhecida como a principal ferramenta para diminuir o pragmatismo, desenvolver o senso crítico e promover a aproximação do aluno com a ciência e a pesquisa".

A Teoria da Contabilidade é o que norteia a execução das atividades ligadas ao exercício da profissão contábil. Inanga e Schneider (2005, p. 233) defendem que "na ausência de teorias fundamentais de contabilidade, contadores são incapazes de avaliar efetivamente o que estão fazendo e oferecer inovação em resposta às novas demandas que possam surgir". Portanto, é importante que os discentes tenham discussões e entendam os assuntos relacionados à Teoria da Contabilidade, principalmente em tempos de mudança, em que se tem a introdução das normas internacionais mais interpretativas e exigem do contador maior capacidade de buscar informações. Neste sentido, Iudícibus (1997, p. 22) cita que "é importante entender bem o que é teoria, bem como seus vários enfoques e metodologias, a fim de os contadores poderem dar respostas ou interpretações satisfatórias para uma série de novos fenômenos que estão a desafiar a nossa profissão".

Além da discussão teórica em relação à disciplina Teoria da Contabilidade, existe uma outra vertente problemática que diz respeito ao momento em que a disciplina deveria ser ofertada, sendo disponibilizada no início do curso, de modo a auxiliar na base teórica da formação acadêmica ou de forma a complementar o conhecimento existente, sendo ofertada no final do curso, partindo do pressuposto da necessidade de conhecimento pré-existente relacionado a alguns conceitos, de forma que o aluno consiga absorve-los satisfatoriamente (Cunha, Borgert, Richartz \& Souza 2014).

Diante da problemática quanto à necessidade de internalização de conteúdos relacionados à disciplina de Teoria da Contabilidade pelos alunos, bem como do momento em que a disciplina deveria ser ofertada aos discentes e considerando as consequências do não conhecimento dos conceitos que são base para a Contabilidade, que influencia no exercício da profissão contábil tanto em relação à credibilidade do profissional da contabilidade que exerce suas atividades sem esse tipo de conhecimento, quanto à desvalorização da profissão como um todo e sua capacidade informacional surge a problemática da pesquisa: qual é a percepção dos graduandos do curso de Ciências Contábeis quanto aos conceitos relevantes ensinados na disciplina de Teoria da Contabilidade? Partindo da questão-problema, tem-se como objetivo principal identificar a compreensão dos graduandos do curso de Ciências Contábeis quanto aos conceitos relevantes ensinados na disciplina Teoria da Contabilidade. Além desse, como objetivos específicos têm-se: (i) verificar o contato dos alunos com alguns conceitos ligados à Teoria da Contabilidade; (ii) identificar as percepções dos alunos quanto à oferta da disciplina Teoria da Contabilidade; e (iii) verificar se há diferença quanto à percepção dos alunos, de acordo com o mercado de trabalho em que esses estão inseridos.

A presente pesquisa contribui para avaliar as questões referentes a problemas enfrentados em relação à disciplina Teoria da Contabilidade. Nesse sentido, o estudo justifica-se pela necessidade de base de conhecimento teórico contábil no exercício da profissão (Lima Filho \& Bruni, 2012), portanto, faz-se necessária a verificação e acompanhamento do ensino dos conceitos da disciplina, sobretudo em um ambiente onde o profissional da contabilidade passa a ter maior poder decisório, mediante as possibilidades de tratamento contábil advindas da convergência com as normas internacionais, necessitando, portanto, de base teórica mais robusta (Borba, Poeta \& Vicente, 2011). Além disso, com base na presente pesquisa e a partir da percepção dos alunos, os docentes podem dar direcionamento aos conceitos que devem ser mais discutidos em sala de aula, bem como as instituições podem avaliar qual o momento mais oportuno para oferta da disciplina que, segundo Cunha et al. (2014), impacta no grau de discussão, interesse e nível de aprendizagem que a disciplina pode proporcionar aos alunos. 


\section{Referencial Teórico}

Nesta seção, aborda-se o ensino da Contabilidade, a Teoria da Contabilidade, os conceitos relevantes da disciplina e estudos anteriores.

\subsection{Ensino da Contabilidade}

Há muito se discute questões relacionadas ao ensino da Contabilidade no Brasil (Santos, 2003). Uma das problemáticas do ensino das Ciências Contábeis é a necessidade de conhecimento pedagógico por parte dos professores. Nossa (1999, p. 19) afirma que "professores que nunca passaram por qualquer formação na área especificamente pedagógica certamente terão agravadas suas características de um profissional adequado para o ensino". Dessa forma, aliado às capacidades da área de domínio do professor, este deve também possuir domínio de como educar (Nossa, 1999).

Ainda aliado a esse problema e advindo das alterações ocorridas nos últimos anos, principalmente a partir dos anos 80, surgiu a necessidade de que o aluno aprenda a aprender (Fahl \& Manhani, 2006) e, além disso, a necessidade de que seja desenvolvida a capacidade crítica (De Araújo \& Andere, 2006). Nesse sentido, Marion (2001 p. 35) afirma que "os estudantes deverão tornar-se "pensadores-críticos", [...] deverão desenvolver a capacidade de autoiniciativa de descobrimento que permita um processo de aprendizagem contínuo e de crescimento em sua vida profissional", desenvolvendo, a partir do estudo da Ciência Contábil, a capacidade de questionar e de tomar decisões (De Araújo \& Andere, 2006).

Beck e Rausch (2015) salientam que a necessidade do desenvolvimento do pensamento crítico nos profissionais da contabilidade é reforçada em função das mudanças advindas da harmonização das normas contábeis. No entanto, antes disso, Franco e Iudícibus (1983) já evidenciavam que ensinar apenas a técnica não era suficiente. Nesse contexto, outra problemática do ensino da Contabilidade relaciona-se ao ensino teórico versus ensino prático, sobretudo em universidades públicas, onde os docentes exercem suas funções sob o regime de dedicação exclusiva.

No tocante a esse ponto, Vasconcellos (1994, p.41) cita que "relacionar a teoria e prática é fator de garantia de competência para o exercício do magistério universitário", de forma que o professor possua e transmita ou desenvolva em seus alunos o conhecimento teórico e o conhecimento prático. Corroborando, Franco (1996) cita que é necessário que os professores dos cursos de Ciências Contábeis complementem seu saber teórico com a experiência prática, bem como com conhecimentos técnicos atualizados.

\subsection{Teoria da Contabilidade}

Hendriksen e Van Breda (2009, p. 32) defendem que a teoria da Contabilidade "pode ser definida como um conjunto coerente de princípios hipotéticos, conceituais e pragmáticos que formam um quadro geral de referências para a investigação da natureza da Contabilidade". Além disso, a teoria Contábil consiste no arcabouço de sustentação das práticas contábeis (Lima Filho \& Bruni, 2012). Sendo assim, o escopo e o conteúdo programático da disciplina relacionada a esse tema são de fundamental importância na formação do profissional da contabilidade (Miranda, Moraes \& Nakao, 2008).

Nesse sentido, a teoria é essencial para a criação e desenvolvimento do conhecimento e da prática Contábil, auxiliando os profissionais quanto ao entendimento sobre os "porquês" de fazer da profissão e não apenas do "fazer" (Marion, 1997), aspecto considerado fundamental por Laffin (2002), que pondera que o ensino baseado apenas no fazer, não possibilita análises com outras perspectivas e exclui a interpretação e a intervenção no processo de ensino. 
Para Pinheiro (1997, p. 5), "deve-se reconhecer a teoria Contábil como um meio de, cada vez mais, aumentar a capacidade de a Contabilidade ser útil aos seus usuários", pois é a partir do desenvolvimento e conhecimento da teoria que os contadores exercem suas funções de forma apropriada e podem fornecer aos seus usuários informações de qualidade e confiáveis. Dessa forma, a disciplina Teoria da Contabilidade deve proporcionar compreensão dos fundamentos do conhecimento contábil (Madeira et al., 2003), além de criar nos alunos a capacidade de realizar julgamentos, respondendo adequadamente às novas demandas.

Barth (2008) defende que a educação contábil não pode concentrar-se em regras, sob o risco de que os conhecimentos adquiridos pelos discentes tornem-se obsoletos em um prazo relativamente curto e, ainda, de não compreenderem determinados conceitos e de não estarem preparados para possíveis mudanças. Portanto, é necessário que os educadores ensinem aos alunos de contabilidade a realizarem julgamentos e a entenderem que nem sempre há apenas uma resposta a determinadas questões, cabendo o julgamento e a tomada de decisões a partir da norma. Dada a importância da disciplina Teoria da Contabilidade e de seu conteúdo, são apresentados a seguir alguns conceitos inerentes à disciplina.

\subsubsection{Conceito de Ativo}

Iudícibus (2009, p. 129) defende que o estudo do ativo é tão importante "que poderíamos dizer que é o capítulo essencial da Contabilidade porque a sua definição e avaliação está ligada à multiplicidade de relacionamentos contábeis que envolvem receitas e despesas".

A definição de ativo está ligada à posse ou controle da entidade e à capacidade de geração de benefícios futuros. Nesse sentido, Hendriksen e Van Breda (2009) o definem como sendo benefícios futuros potenciais de fluxo de serviço ou direitos sob controle da organização. O CPC 00 (R1) (2011) acrescenta a esse conceito o fato de que os ativos devem ser resultantes de eventos passados.

\subsubsection{Goodwill}

O goodwill é tratado por Monobe (1986, p. 65 apud Antunes, \& Martins, 2002) como sendo a diferença entre o valor atual da empresa como um todo e o valor econômico dos seus ativos, sendo, dessa forma, considerado como valor residual. Lima Filho e Bruni (2012, p. 191), baseados em Iudícibus (2009), citam que goodwill pode ser entendido como uma "expectativa de rentabilidade futura, que somente existe se existir lucro anormal, uma vez que os lucros normais, ao serem trazidos os lucros futuros a valor presente pelo custo de oportunidade, tornam-se nulo".

De acordo com o CPC 15 (2011), goodwill "é um ativo que representa benefícios econômicos futuros resultantes dos ativos adquiridos em combinação de negócios, os quais não são individualmente identificados e separadamente reconhecidos".

\subsubsection{Passivo}

Lima Filho e Bruni (2012, p. 191) citam que no passivo há uma inversão do conceito em relação ao ativo, em que "definições de passivo buscam capturar impactos futuros, trocando benefícios gerados por sacrifícios a serem consumidos". Já Hendriksen e Van Breda (2009, p. 410), citando a Financial Accounting Standards Board (Fasb), afirmam que passivos envolvem sacrifícios futuros prováveis econômicos que resultem de obrigações presentes. 
O CPC 00 (R1) (2011) define como sendo "passivo" "toda obrigação presente da entidade, derivada de eventos passados, cuja liquidação se espera que resulte na saída de recursos da entidade capazes de gerar benefícios econômicos". Dessa forma, a definição do CPC incorpora a necessidade de que a obrigação seja resultante de eventos passados.

\subsubsection{Receita e Ganho}

O conceito de receita está ligado aos rendimentos positivos relacionados à atividade principal da empresa, enquanto os ganhos não possuem tal característica (Lima Filho \& Bruni, 2012). Conforme a Fasb (1975 apud Hendriksen \& Van Breda, 2009), receitas "são entradas ou outros aumentos de ativos de uma entidade, ou liquidações de seus passivos (ou ambos), decorrentes da entrega ou produção de bens, prestação de serviços, ou outras atividades correspondentes a operações normais ou principais da entidade". Em contrapartida, Iudícibus (2009), em sua conceituação de receita, considera os ganhos eventuais, diferentemente da Fasb. Para o autor, receitas são ingressos de ativo "sob forma de dinheiro ou direitos a receber, correspondentes, normalmente, à venda de mercadorias, de produtos ou à prestação de serviços, podendo derivar, também, de juros sobre depósitos bancários ou títulos e de outros ganhos eventuais" (Iudícibus, 2009, p. 149).

Para o CPC 30 (R1) (2012), receita é o "ingresso bruto de benefícios econômicos durante o período observado no curso das atividades ordinárias da entidade que resultam no aumento do seu patrimônio líquido, exceto os aumentos de patrimônio líquido relacionados às contribuições dos proprietários". Além disso, para o CPC, os ganhos fazem parte das receitas, definindo-os como "representantes de outros itens que se enquadram na definição de receita e podem, ou não, surgir no curso das atividades usuais da entidade, representando aumentos nos benefícios econômicos" (CPC 30 (R1), 2012).

Iudícibus (2009, p. 159) diz que os ganhos representam "um resultado líquido favorável resultante de transações ou eventos não relacionados às operações normais do empreendimento". Seguindo essa linha, Kam (1986) cita que "ganhos são aumentos em ativos líquidos, provenientes de operações periféricas ou incidentais, e de outros eventos que podem estar em grande parte além do controle da firma”.

\subsubsection{Despesa e Perda}

Opostamente às receitas e aos ganhos, as despesas e as perdas representam uma redução em termos de resultado para as empresas. Conforme Hendriksen e Van Breda (2009, p. 232), as despesas "constituem o uso ou consumo de bens e serviços no processo de obtenção de receitas". Nesse mesmo sentido, Kam (1986) diz que as "despesas são reduções no valor dos ativos ou aumento no valor das exigibilidades, devido à utilização de bens e serviços das operações principais ou centrais da entidade".

Para o CPC 00 (R1) (2011), despesas são:

Decréscimos nos benefícios econômicos durante o período contábil, sob a forma da saída de recursos ou da redução de ativos ou assunção de passivos, que resultam em decréscimo do patrimônio líquido, e que não estejam relacionados com distribuições aos detentores dos instrumentos patrimoniais.

Assim como alguns autores defendem para os ganhos, as perdas podem ser vistas como aquelas reduções em termos de resultados que possuem um caráter eventual, sem ter ligação com a atividade-fim da empresa (Lima Filho \& Bruni, 2012). Já Iudícibus (2009) conceitua as perdas como sendo um efeito líquido, dado que não haverá confronto, como o da despesa com a receita, e que não surge das operações habituais da empresa. Para o CPC, assim como na definição de ganho, as perdas "representam outros itens que se enquadram na definição de despesas e podem ou não surgir no curso das atividades usuais da entidade, representando decréscimos nos benefícios econômicos" (CPC 00 (R1) (2011). 


\subsubsection{Outros Conceitos Relevantes}

Além dos conceitos principais, outros possuem relativa importância ao exercício e entendimento da profissão contábil ou são considerados temas emergentes em contabilidade, sendo alguns deles: Passivo Ambiental (Lima Filho \& Bruni, 2012; Ribeiro, 2014; Calixto, 2006), Earnings Management (Murcia, Rover, Souza \& Borba, 2008), Teoria da Agência (Iudícibus, 2012; Ribeiro, 2013; Cardoso, Pereira \& Guerreiro, 2007) e Governança Corporativa (Murcia et al., 2008; Iudícibus, 2012; Ribeiro, 2013).

Lima Filho e Bruni (2012) definem que passivos são obrigações e, dessa forma, os passivos ambientais são tratados como sendo obrigações presentes em termos de recuperação, preservação e proteção relacionados ao meio ambiente que irão gerar desembolsos futuros. Esse passivo, além da evidenciação em função da responsabilidade social, em certas empresas, principalmente aquelas que degradam em algum grau o meio ambiente, possui impacto significativo nos resultados e, consequentemente, na capacidade de continuidade da organização. Sendo assim, a correta evidenciação de passivos ambientais impacta a avaliação dessas organizações (Ribeiro \& Lisboa, 1999; Bae \& Sami, 2005).

Earnings Management, Gerenciamento de Lucros, Contabilidade Criativa ou Gerenciamento de Resultados Contábeis (Matsumoto \& Parreira, 2007) é o nome dado à utilização de práticas contábeis com a finalidade de obtenção dos resultados desejados, levando a distorções das informações contábeis e, consequentemente, das análises realizadas com base nessas informações (Rodrigues, 2007). Esse conceito é composto de duas palavras: gerenciamento e lucro ou resultado. Portanto, trata-se da manipulação do resultado, geralmente de acordo com as práticas e princípios contábeis aceitos, por meio de escolhas contábeis discricionárias, de forma a evidenciar uma imagem da empresa de acordo com os interesses dos gestores (Santos \& Grateron, 2003; Matsumoto \& Parreira, 2007).

Apesar disso, conforme evidenciado por Nardi e Nakao (2009), não há consenso quanto à definição de gerenciamento de resultados, principalmente no que tange a sua legalidade, sendo vista como algo negativo por alguns autores, em que há a intenção de enganar os usuários das informações contábeis e por outros como algo normal e inerente à prática contábil e às escolhas decorrentes dela.

À medida que as organizações se desenvolvem, faz-se necessário que o proprietário (principal) transfira responsabilidades e controles aos administradores (agentes). Essa nova configuração, em termos de controle, leva a um conflito de interesses entre os agentes e o principal, dado que cada parte irá tomar suas decisões de acordo com os seus interesses, e, além disso, nem sempre os usuários possuem as mesmas informações, existindo, portanto, uma assimetria informacional (Nascimento \& Bianchi, 2005). Nesse sentido, a teoria da Agência relaciona-se ao fato de que cada decisão tomada pode beneficiar um lado e, em contrapartida, ser desfavorável ao outro, dado que cada agente possui seus próprios interesses, e buscará maximizá-los (Nardi \& Nakao, 2009). Adicionalmente, Lopes e Iudícibus (2012) citam as peculiaridades envolvidas na teoria da Agência como o fato de haver envolvimento de diversas pessoas e de diversos incentivos. A existência de assimetria informacional e coordenação de esforços.

Ainda no tocante aos problemas entre agente e principal, De Carvalho (2002, p. 19) afirma que a governança corporativa pode ser entendida como "um conjunto de regras que visa minimizar os problemas de agência”. Nesse sentido, Pereira, Bruni, Rocha, Lima Filho e Faria (2010) defendem que a governança corporativa deriva dos problemas de agência e da assimetria informacional, mas não se limita a eles, buscando minimizar outros desalinhamentos nas organizações. 


\subsection{Estudos Anteriores Sobre a Disciplina Teoria da Contabilidade}

Lima Filho e Bruni (2012) realizaram uma pesquisa com graduandos do curso de Ciências Contábeis, em Salvador (BA), com o objetivo de aferir a compreensão de alguns termos explorados no contexto da disciplina Teoria da Contabilidade. Para tal, foram aplicados questionários com questões relacionadas aos conceitos de ativos, passivos, goodwill, receitas, despesas, ganhos e perdas a 591 alunos que já haviam cursado a disciplina Teoria da Contabilidade. Os autores identificaram que os alunos possuem falhas na compreensão de conceitos contábeis relevantes e observaram, ainda, que há diferença quanto à compreensão dos conceitos entre os alunos das instituições públicas e privadas, sendo que, nas instituições públicas, os alunos apresentaram melhor domínio dos conceitos pesquisados.

Em sua pesquisa Piccoli, Chiarello e Klann (2015) tinham como objetivo identificar a percepção dos acadêmicos do curso de Ciências Contábeis quanto a conceitos estudados na disciplina Teoria da Contabilidade e sua relação com as demais disciplinas do curso. A partir da aplicação de um questionário em três instituições privadas do Oeste e Extremo Oeste de Santa Catarina, os autores obtiveram 163 respostas, sendo que parte dos alunos já haviam realizado a disciplina, e parte dos alunos iriam cursá-la no futuro. Os resultados mostram que a maior parte dos alunos considera a disciplina Teoria da Contabilidade importante para a sua profissão e que alunos mais novos (17 a 21 anos) apresentam maior compreensão acerca dos conceitos relativos à disciplina.

Cunha et al. (2014) realizaram um estudo buscando identificar a percepção dos professores e alunos da disciplina Teoria da Contabilidade no que tange ao momento de sua oferta durante o curso de graduação. A pesquisa foi realizada com professores da disciplina e alunos que já cursaram ou estão cursando a disciplina em duas universidades públicas em Santa Catarina: Universidade Federal de Santa Catarina (UFSC) e Universidade do Estado de Santa Catarina (Udesc), sendo os dados obtidos por meio da aplicação de questionário. Os autores identificaram que na Udesc aproximadamente $45 \%$ dos alunos afirmam não ter dificuldade para acompanhar a disciplina, enquanto na UFSC, apenas $12 \%$ fazem essa afirmação. Além disso, 85\% dos alunos da Udesc consideraram como oportuno o momento em que a disciplina é oferecida no seu curso (em duas etapas, uma na primeira fase e outra na sétima); já na UFSC a disciplina é ofertada em momento oportuno para apenas $41 \%$ dos alunos (em etapa única, na sétima fase do curso).

\section{Procedimentos Metodológicos}

Neste tópico são apresentados o enquadramento e os procedimentos metodológicos utilizados para a realização desta pesquisa, divididos em "enquadramento metodológico", "procedimentos para elaboração do questionário" e "população e amostra".

A pesquisa foi realizada em instituições de ensino públicas e privadas na região da grande Florianópolis (SC), selecionadas por conveniência; para a coleta dos dados, foi utilizada a aplicação de questionário. Quanto aos objetivos, considera-se uma pesquisa descritiva, visto que foram coletados dados com o objetivo de descrever a realidade observada (Triviños, 1987). No que diz respeito aos procedimentos, trata-se de um levantamento, realizado por meio da interrogação dos alunos a partir do questionário, permitindo a coleta de dados e posterior análise (Gil, 2002). Em relação à abordagem, a pesquisa é qualitativa, em que, a partir dos dados coletados, foram feitas análises de forma construtivista, com base em um raciocínio indutivo (Creswell, Hanson, Plano \& Morales, 2007).

O questionário foi elaborado a partir da definição dos objetivos gerais e específicos da pesquisa, com questionamentos que dessem suporte para a resolução da questão-problema. Para auxiliar nesse processo, foi utilizado como base o questionário de Lima Filho e Bruni (2012). Além disso, um pré-teste foi realizado a 3 alunos, buscando identificar possíveis problemas na elaboração do questionário ou possíveis dúvidas durante a sua aplicação, resultando em ajustes para o aperfeiçoamento do instrumento de pesquisa. 
Primeiramente foram identificadas todas as instituições de ensino credenciadas na Grande Florianópolis, considerando os municípios de Florianópolis, São José, Biguaçu e Palhoça, a partir dos dados do MEC. Após a identificação das IES e obtenção do contato com as instituições via acesso aos seus sítios eletrônicos, foi realizado contato via e-mail ou telefone com cada instituição para verificar o interesse em fazer parte da pesquisa. Dessa forma, a amostra é composta de todas as instituições de ensino superior que ofertam o curso de Ciências Contábeis na modalidade presencial na grande Florianópolis (SC) e que se dispuseram a participar da pesquisa.

Após essa etapa, foi feita a aplicação definitiva dos questionários, por meio de aplicação presencial aos discentes do período superior àquele em que a disciplina de Teoria da Contabilidade é ofertada na instituição, ou por meio de questionário virtual na plataforma Google Docs. A análise dos dados foi realizada por meio do Microsoft Excel, buscando responder aos objetivos da pesquisa.

Foram identificadas 16 IES credenciadas no MEC, com a oferta do curso de Ciências Contábeis na modalidade "presencial". Não foi possível a aplicação desta pesquisa em 5 das 16 instituições identificadas, sendo pela não oferta desta disciplina específica pela instituição, pela instituição não ofertar mais o curso na modalidade presencial ou por não obtenção do contato. A aplicação do questionário ocorreu entre os dias 3 e 28 de agosto de 2015, obtendo um total de 65 respondentes que haviam cursado a disciplina Teoria da Contabilidade.

\section{Apresentação e Análise dos Resultados}

Neste tópico são apresentadas as análises dos dados e os resultados obtidos. O tópico é dividido da seguinte forma: perfil dos respondentes; conceitos aplicados à Teoria da Contabilidade; contato com conceitos relacionados à Teoria da Contabilidade; disciplina de Teoria da Contabilidade; e relação entre área e tempo de atuação; e conceitos de ativo e passivo.

\subsection{Perfil dos Respondentes}

Quanto às idades dos respondentes, 60\% dos alunos possuem idade entre 21 e 24 anos, sendo que a maioria, $18,5 \%$, possui 21 anos, sendo a amplitude da idade dos alunos de 25 anos, com a menor idade (18) e a maior (43).

Dos 65 respondentes, $83 \%$ afirmaram possuir atividade remunerada, sendo que desses a maior parte (30\%) atua no serviço público. Além disso, 26\% atuam em outras áreas (ou seja, não contábil), em empresas; $21 \%$ atuam em área contábil, em empresas; $15 \%$ em escritórios de contabilidade; e $8 \%$ em outros. Além disso, quanto ao tempo de atuação na área, a maior parte (68\%) dos respondentes já atuou em áreas afins da contabilidade, sendo que desses, 35\% possui experiência de 1 a 3 anos; $22 \%$ possui até 1 ano de experiência; $8 \%$ possui de 3 a 6 anos; e apenas $3 \%$ possui mais de 6 anos de experiência na área contábil.

Os alunos foram questionados também quanto a outras formações que pudessem possuir e $88 \%$ dos respondentes não possuem outras formações. Dos respondentes que possuem outras formações, apenas 1 aluno (2\%) possui técnico em contabilidade; 2\% possuem outra graduação; e 9\% possuem técnico em outras áreas do conhecimento.

Em relação à atividade após a obtenção do título de bacharel em Ciências Contábeis, a maior parte dos alunos (50\%) pretende inserir-se no setor público. Além disso, $40 \%$ dos pesquisados pretendem inserir-se no setor privado (como funcionário ou proprietário); $9 \%$ tem por objetivo a área acadêmica, como professor e pesquisador; e 1\% não pretende trabalhar na área, seguindo com outra graduação após a finalização do curso de Ciências Contábeis. 


\subsection{Conceitos aplicados à Teoria da Contabilidade}

Este bloco tem como objetivo verificar a percepção dos alunos quanto a alguns conceitos ensinados em Teoria da Contabilidade, no sentido de identificar se os alunos veem esses conceitos de forma mais alinhada à teoria ou às normas contábeis.

Como norma foram considerados os pronunciamentos emitidos pelo Comitê de Pronunciamento Contábeis (CPC). Em relação ao ativo, 80\% dos alunos consideraram como sendo aquele que mais expressa o seu entendimento o conceito emitido pelo CPC, como pode ser visto na Figura1.

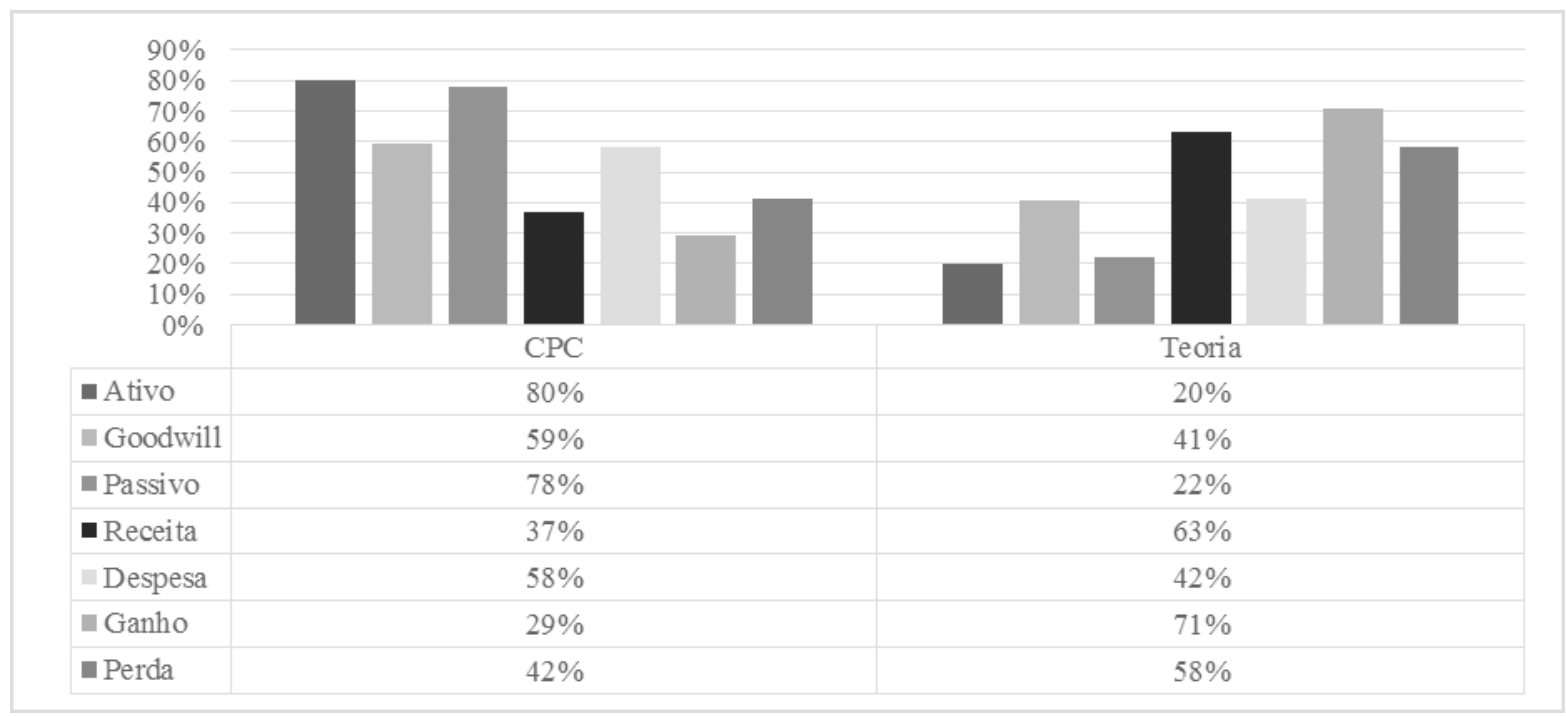

Figura 1. percepção dos alunos quanto aos conceitos de Teoria da Contabilidade.

Fonte: Dados da pesquisa (2015)

Essa situação, em que o conceito emitido pelo CPC foi considerado como o que melhor expressa o entendimento do aluno aconteceu também para os conceitos do goodwill, de passivo e de despesa, em que $59 \%, 78 \%$ e $58 \%$ dos alunos, respectivamente, assinalaram o conceito conforme o CPC.

O conceito de receita, conforme a teoria, foi considerado como sendo mais representativo do entendimento dos respondentes em $63 \%$ dos casos, sendo que o mesmo caso ocorreu com o conceito de ganho e de perda, em que no primeiro caso, $71 \%$ dos respondentes consideraram o conceito da teoria mais representativo e, no segundo caso, o conceito de acordo com a teoria foi considerado mais representativo para $58 \%$ dos respondentes.

Esses resultados corroboram, em parte, os achados de Piccoli et al. (2015), em que foi identificado que os conceitos de ativo, passivo, receita e despesa não são totalmente dominados pelos discentes, sendo percebidos como conceitos simples, sem aprofundamento teórico, enquanto os conceitos de perda e ganho foram entendidos de forma mais complexa pelos alunos. Além disso, os conceitos selecionados como sendo mais representativos do entendimento dos temas pelos respondentes, de forma geral, foram aqueles emitidos pelo CPC, o que indica que os alunos têm focado seu pensamento e conhecimento para as regras emitidas pelos órgãos, não vislumbrando as questões contábeis mais amplamente, com fundamentos da teoria, resultado similar ao encontrado por Lima Filho e Bruni (2012), em que os alunos evidenciaram definições para os conceitos pesquisados de forma pouco reflexiva, desatualizada e fora do contexto de discussões teóricas. 


\subsection{Contato com Conceitos Relacionados à Teoria da Contabilidade}

Nessa etapa da pesquisa, os alunos foram questionados quanto ao seu contato com os seguintes tópicos relacionados à Teoria da Contabilidade: Passivo Ambiental, Earnings Management (gerenciamento de resultados), Governança Corporativa e Teoria da Agência.

Como pode ser observado na Tabela 1,43\% dos respondentes já tiveram algum contato com o passivo ambiental, porém todos de forma superficial. Além disso, $46 \%$ nunca teve oportunidade de discutir esse assunto e $11 \%$ desconhece totalmente. Sendo assim, a maioria dos respondentes (57\%) não conhece ou nunca teve oportunidade de discutir esse tema, seja na disciplina Teoria da Contabilidade, em eventos ou outros cursos.

Tabela 1:

Frequência de contato dos respondentes.

\begin{tabular}{lcccc}
\hline \multicolumn{1}{c}{ Respostas } & Passivo Ambiental & $\begin{array}{c}\text { Earnings } \\
\text { Management }\end{array}$ & $\begin{array}{c}\text { Governança } \\
\text { Corporativa }\end{array}$ & Teoria da Agência \\
\hline $\begin{array}{l}\text { Sim e com } \\
\text { profundidade }\end{array}$ & $0 \%$ & $3 \%$ & $28 \%$ & $14 \%$ \\
\hline $\begin{array}{l}\text { Sim, mas muito } \\
\text { superficialmente }\end{array}$ & $43 \%$ & $12 \%$ & $58 \%$ & $29 \%$ \\
\hline $\begin{array}{l}\text { Nunca tive } \\
\text { oportunidade de } \\
\text { discutir esse assunto }\end{array}$ & $46 \%$ & $60 \%$ & $14 \%$ & $29 \%$ \\
\hline $\begin{array}{l}\text { Desconheço } \\
\text { inteiramente esse } \\
\text { assunto }\end{array}$ & $11 \%$ & $25 \%$ & $0 \%$ & $28 \%$ \\
\hline
\end{tabular}

Fonte: dados da pesquisa (2015)

Quanto ao conceito de Earnings Management ou gerenciamento de resultados contábeis, a maior parte, $60 \%$ dos alunos respondentes, nunca teve oportunidade de discutir esse assunto, além disso, $25 \%$ desconhece totalmente o tema. Entre os $15 \%$ que já tiveram oportunidade de discutir este conceito, apenas $3 \%$ o fizeram em profundidade.

Entre os termos pesquisados, governança corporativa foi o termo que mais os alunos tiveram oportunidade de discutir. Entre os alunos respondentes, $86 \%$ assinalaram que já tiveram oportunidade de discutir esse conceito, sendo que desses, $28 \%$ já teve oportunidade de discutir com profundidade o assunto. Já em relação à teoria da Agência, $43 \%$ dos respondentes afirmou já ter tido oportunidade de discutir o assunto, porém a maior parte desses (29\%), de forma superficial. Em contrapartida, 29\% afirmou nunca ter tido oportunidade de discutir esse conceito e $28 \%$ o desconhece totalmente.

Esses resultados indicam que, apesar de serem temas emergentes e de relevância na profissão contábil, não têm sido abordados ou discutidos em profundidade nos cursos de Ciências Contábeis, fato que pode levar a deficiências quanto à formação do profissional da contabilidade. 


\subsection{Disciplina de Teoria da Contabilidade}

Este bloco trata de algumas considerações quanto à oferta da disciplina Teoria da Contabilidade, como a sua importância e período em que ela deve ser ofertada.

Para a maior parte dos respondentes (43\%), a disciplina Teoria da Contabilidade possui fundamental importância na formação profissional dos alunos de Ciências Contábeis. Apenas 5\% dos respondentes consideram a disciplina com pouca ou nenhuma importância, corroborando o resultado encontrado por Piccoli et al. (2015), em que 80\% dos alunos afirmaram considerar a disciplina importante para o seu aprendizado. Adicionalmente, os alunos foram questionados se a disciplina deveria ser desmembrada em mais de uma ao longo do curso, e a maioria (52\%) respondeu que ela não deveria ser dividida. Para os $48 \%$ que responderam que ela deveria ser desmembrada, $77 \%$ dos alunos afirmaram que deveria haver duas disciplinas relacionadas à Teoria da Contabilidade ao longo do curso.

Em relação ao período de oferta da disciplina, $71 \%$ dos respondentes discordam do período em que ela é ofertada. Esses respondentes foram questionados em qual período ela deveria ser ministrada e $87 \%$ afirmaram que ela deveria ser oferecida nos períodos iniciais do curso até a $4^{a}$ fase, sendo que, para a maioria desses, o melhor período para a oferta da disciplina seria o primeiro, corroborando um dos resultados de Cunha et al. (2014), em que para 64\% dos alunos pesquisados da Udesc, a disciplina deveria ser ofertada no primeiro período, servindo de base ao conhecimento dos alunos.

Além disso, os alunos foram questionados se essa disciplina poderia ser eliminada e cada professor ministrar o conteúdo dessa em suas disciplinas. Para $89 \%$ dos respondentes, a disciplina Teoria da Contabilidade não deve ser eliminada, sendo seu conteúdo ministrado em uma disciplina específica. Esse resultado corrobora o resultado apresentado por Ferreira et al. (2012), em que os professores foram questionados e $64 \%$ afirmou ser importante ou muito importante ter uma disciplina específica de Teoria da Contabilidade para a graduação.

\subsection{Relação entre Área e Tempo de Atuação e Conceitos de Ativo e Passivo}

Primeiro foi feita a análise da relação da área de atuação dos respondentes com a percepção dos conceitos de ativo e passivo e, posteriormente, análise entre o tempo de atuação e a percepção desses conceitos. Os dados demonstram que a área de atuação não influencia a percepção dos alunos quanto aos conceitos de ativo e passivo, dado que, em ambos os casos e em todas as áreas de atuação, o conceito de $\mathrm{CPC}$ foi selecionado pela maioria dos respondentes como sendo o que mais representa o seu entendimento acerca do tema, como pode ser observado nas tabelas 2 e 3 .

Tabela 2:

Relação entre área de atuação e o conceito de ativo.

\begin{tabular}{lccccc}
\hline \multicolumn{1}{c}{ Ativo } & CPC & Teoria & Total & CPC & Teoria \\
\hline Escritório contábil & 7 & 1 & 8 & $88 \%$ & $13 \%$ \\
\hline Atuação na área contábil em empresa & 7 & 4 & 11 & $64 \%$ & $36 \%$ \\
\hline Atuação em outra área em empresa & 11 & 4 & 15 & $73 \%$ & $27 \%$ \\
\hline Serviço público & 13 & 3 & 16 & $81 \%$ & $19 \%$ \\
\hline Outros & 4 & 0 & 4 & $100 \%$ & $0 \%$ \\
\hline
\end{tabular}

Fonte: dados da pesquisa (2015)

Portanto, não se pode observar, com base nos dados, que há relação entre a área de atuação e a percepção dos alunos quanto aos conceitos de ativo e passivo. 
Tabela 3:

Relação entre área de atuação e o conceito de passivo.

\begin{tabular}{|c|c|c|c|c|c|}
\hline Passivo & CPC & Teoria & Total & CPC & Teoria \\
\hline Escritório contábil & 6 & 2 & 8 & $75 \%$ & $25 \%$ \\
\hline Atuação na área contábil em empresa & 8 & 3 & 11 & $73 \%$ & $27 \%$ \\
\hline Atuação em outra área em empresa & 12 & 2 & 14 & $86 \%$ & $14 \%$ \\
\hline Serviço público & 11 & 5 & 16 & $69 \%$ & $31 \%$ \\
\hline Outros & 4 & 0 & 4 & $100 \%$ & $0 \%$ \\
\hline
\end{tabular}

Fonte: dados da pesquisa (2015)

Quanto ao tempo de atuação na área contábil e sua influência na percepção dos graduandos quanto aos conceitos de ativo e passivo, pode-se observar algumas relações. No que diz respeito ao conceito de ativo, observa-se, com base nos respondentes, que, entre alunos com experiência de até 1 ano, não há diferença quanto à percepção de um conceito ou de outro.

Tabela 4:

Relação entre tempo de atuação e o conceito de ativo.

\begin{tabular}{lcccccc}
\hline & Ativo & CPC & Teoria & Total & CPC & Teoria \\
\hline Até 1 ano & 7 & 7 & 14 & $50 \%$ & $50 \%$ & $9 \%$ \\
\hline De 1 a 3 anos & 20 & 2 & 22 & $91 \%$ & $20 \%$ & $0 \%$ \\
\hline De 3 a 6 anos & 4 & 1 & 5 & $80 \%$ & $100 \%$ & \\
\hline Mais de 6 anos & 2 & 0 & 2 & 20 & $85 \%$ & $15 \%$ \\
\hline Nunca atuei na área & 17 & 3 & & & \\
\hline
\end{tabular}

Fonte: dados da pesquisa (2015)

No entanto, em relação às outras faixas de experiência, não houve dúvidas quanto ao conceito, dado que em todas as faixas (exceto até 1 ano) o conceito escolhido como sendo o mais representativo da percepção dos respondentes foi o do CPC.

Quanto ao passivo, também houve uma faixa em que, aparentemente, não há diferença entre os conceitos. Para os estudantes com mais de 6 anos de experiência, ambos os conceitos tiveram a mesma representatividade, como pode ser visto na Tabela 5, no entanto, com um número pequeno de respondentes, o que pode influenciar esse resultado, especificamente.

Tabela 5:

Relação entre tempo de atuação e o conceito de passivo.

\begin{tabular}{lcccccc}
\hline & Passivo & CPC & Teoria & Total & CPC & Teoria \\
\hline Até 1 ano & 12 & 2 & 14 & $86 \%$ & $14 \%$ \\
\hline De 1 a 3 anos & 15 & 7 & 22 & $68 \%$ & $32 \%$ & $20 \%$ \\
\hline De 3 a 6 anos & 4 & 1 & 5 & $80 \%$ & $50 \%$ \\
\hline Mais de 6 anos & 1 & 1 & 2 & $50 \%$ & $15 \%$ \\
\hline Nunca atuei na área & 17 & 3 & 20 & $85 \%$ & & 1 \\
\hline
\end{tabular}

Fonte: dados da pesquisa (2015)

Em todas as outras faixas de atuação, o conceito que prevaleceu como sendo o mais representativo foi o do CPC. Portanto, em relação ao passivo, também não se pode identificar uma relação entre tempo de atuação e percepção diferenciada dos conceitos. 
Esses resultados podem indicar que o exercício da profissão contábil não é um fator de grande influência para a percepção dos conceitos relacionados à Teoria da Contabilidade e, portanto, o conhecimento adquirido em sala de aula, de forma ampliada e com base na teoria pode auxiliar os estudantes no seu desenvolvimento profissional.

\section{Conclusões}

O presente estudo teve por objetivo identificar a percepção dos graduandos do curso de Ciências Contábeis quanto aos conceitos relevantes ensinados na disciplina Teoria da Contabilidade, buscando ainda verificar se há relação entre a percepção dos alunos e sua área de atuação e suas percepções relacionadas à oferta da disciplina. Além disso, buscou-se verificar o contato dos discentes com alguns conceitos relacionados à Teoria da Contabilidade.

Com base nos dados obtidos, observou-se que os alunos percebem os conceitos de Teoria da Contabilidade mais ligados à normatização, dado que a maior parte dos alunos considerou o conceito publicado pelos CPC, como sendo aquele que mais representa o seu entendimento acerca dos conceitos pesquisados. Resultado esse que possui uma implicação para o atual momento da Contabilidade, de convergência das normas para com as internacionais, em que há um maior grau de discricionariedade cujos os profissionais da contabilidade precisam interpretar as normas e, a partir disso, tomar a melhor decisão possível, dentro das possibilidades existentes.

O comportamento identificado nesta pesquisa revela que os alunos têm se limitado às normas e sua especificidade, não buscando a interpretação dos conceitos de acordo com a teoria, podendo gerar uma desatualização desses profissionais em um curto período de tempo, em decorrência das mudanças advindas da adoção das normas internacionais. Além disso, no tocante ao ensino da Contabilidade, esses resultados podem indicar um gap quanto à atualização dos professores e, consequentemente, na forma como a normatização é transmitida aos alunos, não desenvolvendo nesses a capacidade crítica e de julgamento.

Assim como a literatura considera a Teoria da Contabilidade e seu entendimento importante, os alunos também veem dessa forma e consideram importante que esse conteúdo esteja sintetizado em uma disciplina, de forma a auxiliá-los no entendimento sobre conceitos contábeis relevantes.

De forma geral, os resultados desta pesquisa fornecem insights para que as instituições de ensino direcionem os conteúdos da disciplina Teoria da Contabilidade de forma a desenvolver nos discentes a capacidade crítica e de debate quanto à identificação e à conceituação de temas relacionados à área contábil, tanto quanto a principais conceitos, como ativo e passivo, quanto em relação aos temas emergentes, e, principalmente, quanto a esses últimos, dado que são temas que, em função das condições atuais, possuem impacto no exercício da profissão e necessitam ser discutidos em profundidade com os alunos, o que, segundo os resultados obtidos, não vem ocorrendo, já que a maior parte dos alunos nunca teve oportunidade de discutir ou desconhece totalmente a grande parte dos temas pesquisados, cabendo às universidades a decisão de inserir discussões atuais nas disciplinas. Além disso, este estudo pode auxiliar na identificação de gaps de ensino resultantes das alterações sofridas pela Contabilidade nos últimos anos e a possível desatualização dos docentes quantos ao conhecimento técnico ou quanto à forma de desenvolver nos alunos as capacidades exigidas atualmente. 
Contribui-se, ainda, para a evolução do tema pesquisado, sobretudo ao fazer novas relações com fatores que podem influenciar na percepção dos conteúdos por parte dos discentes, como área e tempo de atuação. Pode-se perceber que esses fatores não influenciam a percepção dos alunos de Ciências Contábeis quanto aos conceitos de ativo e passivo, reforçando, portanto, a ênfase que deve ser dada ao ensino acadêmico desses conceitos, de forma a permitir que o aluno desenvolva, nessa etapa de sua carreira profissional, a capacidade de julgamento necessária ao desenvolvimento da atividade contábil. Em termos profissionais, contribui-se ao identificar a necessidade de educação continuada decorrente do fato de que se percebe que o ensino ofertado na graduação não é exaustivo e suficiente para que esses profissionais estejam preparados para as mudanças que possam ocorrer, baseando-se na teoria, necessitando, portanto, atualizar-se e obter novos conhecimentos a cada modificação ocorrida na legislação e na prática contábil.

Recomenda-se que este estudo seja aplicado em instituições de ensino que ofertem o curso na modalidade "a distância" com a finalidade de identificar se há disparidade entre as modalidades de ensino. Além disso, sugerem-se estudos que busquem verificar a existência dos gaps citados no ensino da Teoria da Contabilidade, bem como seja analisada se a forma como os alunos têm sido submetidos aos ensinamentos contábeis influencia na percepção destes quanto aos conceitos relevantes em Teoria da Contabilidade.

\section{Referências}

Antunes, M. T. P., \& Martins, E. (2002). Capital intelectual: verdades e mitos. Revista Contabilidade \& Finanças, 13(29), pp. 41-54. http://dx.doi.org/10.1590/S1519-70772002000200003

Bae, B., \& Sami, H. (2005). The effect of potential environmental liabilities on earnings response coefficients. Journal of Accounting, Auditing \& Finance, 20(1), pp. 43-70.

Barth, M. E. (2008). Global financial reporting: Implications for US academics. The Accounting Review, 83(5), pp. 1159-1179. http://dx.doi.org/10.2308/accr.2008.83.5.1159

Beck, F., \& Rausch, R. B. (2015). Fatores que influenciam o processo ensino-aprendizagem na percepção de discentes do curso de ciências contábeis. Contabilidade Vista \& Revista, 25(2), pp. 38-58.

Bezerra, C. G. (2015). Um estudo da disciplina Teoria da Contabilidade em instituições de ensino superior públicas da grande Florianópolis considerando a ementa da disciplina e a satisfação dos alunos. In Congresso UFSC de Controladoria e Finanças, 6.

Bezerra, C. G. (2015). Um estudo da disciplina Teoria da Contabilidade em instituições de ensino superior públicas da grande Florianópolis considerando a ementa da disciplina e a satisfação dos alunos. Anais do Congresso UFSC de Controladoria e Finanças, Florianópolis, SC, Brasil, 6.

Borba, J. A., Poeta, F. Z., \& Vicente, E. F. R. (2011). Teoria da contabilidade: uma análise da disciplina nos programas de mestrado brasileiros. Sociedade, Contabilidade e Gestão, 6(2).

BRASIL. Resolução no 3, de 5 de outubro de 1992 (2004). Fixa os mínimos de conteúdo e duração do curso de graduação em Ciências Contábeis. Conselho Federal de Educação. Brasília, DF, s. 1, p. 15.

Calixto, L. (2006). O ensino da contabilidade ambiental nas universidades brasileiras: um estudo exploratório. Revista Universo Contábil, 2(3), pp. 65-78.

Cardoso, R. L., Pereira, C. A., \& Guerreiro, R. (2007). Perfil das pesquisas em contabilidade de custos apresentadas no EnANPAD no período de 1998 a 2003. Revista de Administração Contemporânea, 11(3), pp. 177-198. http://dx.doi.org/10.1590/S1415-65552007000300009

Comitê de Pronunciamentos Contábeis (CPC). Combinação de Negócios. Recuperado em 30 de julho, 2015, de http://www.cpc.org.br/CPC. 
Comitê de Pronunciamentos Contábeis (CPC). Estrutura Conceitual para Elaboração e Divulgação de Relatório Contábil-Financeiro. Recuperado em 30 de julho, 2015, de http://www.cpc.org.br/CPC.

Comitê de Pronunciamentos Contábeis (CPC). Receitas. Recuperado em 30 de julho, 2015, de http://www. cpc.org.br/CPC.

Creswell, J. W., Hanson, W. E., Plano, V. L. C., \& Morales, A. (2007). Qualitative research designs selection and implementation. The counseling psychologist, 35(2), pp. 236-264. http://dx.doi. org/10.1177/0011000006287390

Cunha, L. C., Borgert, A., Richartz, F., \& Souza, F. R. de (2014). A Disciplina Teoria da Contabilidade em Cursos de Graduação: Percepção de Alunos e Professores. Anais Congresso UFSC de Controladoria e Finanças, Florianópolis, Santa Catarina, Brasil, 5.

De Araújo, A. M. P., \& Andere, M. A. (2006). Análise das Competências do Professor do Ensino Superior em Contabilidade: um estudo exploratório. In Anais do Congresso Brasileiro de Custos-ABC, 13.

De Araújo, A. M. P., \& Andere, M. A. (2006). Análise das Competências do Professor do Ensino Superior em Contabilidade: um estudo exploratório. Anais do Congresso Brasileiro de Custos-ABC, Porto de Galinhas, PE, Brasil, 13.

De Carvalho, A. G. (2002). Governança corporativa no Brasil em perspectiva. Revista de Administração da Universidade de São Paulo, 37(3), pp. 19-32.

Fahl, A. C., \& Manhani, L. P. De S. (2006). As perspectivas do profissional contábil e o ensino da contabilidade. Revista de Ciências Gerenciais, 10(12), pp. 25-33. http://dx.doi.org/10.17921/1415$-6571.2006 \mathrm{v} 10 \mathrm{n} 12 \mathrm{p} 25-33$

Ferreira, A. F., Splitter, K., \& Borba, J. A. (2012). Teoria da contabilidade: uma disciplina específica ou conhecimentos que deveriam estar integrados em outras disciplinas. Anais Congresso USP de Controladoria e Contabilidade, São Paulo, SP, Brasil, 12.

Franco, H. (1996). Cursos de pós-graduação, educação profissional continuada e valorização da profissão contábil. Revista Brasileira de Contabilidade, 26(103).

Franco, H, \& Iudícibus, S. (1983). A contabilidade na era da globalização. São Paulo, Atlas.

Gil, A. C. (2002). Como elaborar projetos de pesquisa. São Paulo, 5.

Hendriksen, E. S., \& Van Breda, M. F. (2009). Teoria da contabilidade; tradução de Antônio Zoratto Sanvicente. São Paulo, Atlas.

Inanga, E. L., \& Schneider, W. B. (2005). The failure of accounting research to improve accounting practice: a problem of theory and lack of communication. Critical Perspectives on Accounting, 16(3), pp. 227-248. http://dx.doi.org/10.1016/S1045-2354(03)00073-X

Iudícibus, S. de (1997). O verdadeiro significado de uma teoria. Revista Brasileira de Contabilidade, 25(97), pp. 21-23.

Iudícibus, S. de (2009). Teoria da Contabilidade. São Paulo, Atlas, 9.

Iudícibus, S. de (2012). Teoria da Contabilidade: evolução e tendências. Revista de Contabilidade do Mestrado em Ciências Contábeis da UERJ, 17(2), pp. 5-13.

Kam, V. (1986). Accounting theory. New York: Wiley.

Laffin, M. (2002). Ensino da contabilidade: componentes e desafios. Contabilidade Vista \& Revista, 13(3), pp. 9-20.

Lima Filho, R. N., \& Bruni, A. L. (2012). Percepção dos graduandos em Ciências Contábeis de Salvador (BA) sobre os conceitos relevantes da Teoria da Contabilidade. Revista de Educação e Pesquisa em Contabilidade (REPeC), 6(2), pp. 187-203. http://dx.doi.org/10.17524/repec.v6i2.176 
Lopes, A. B., \& Iudicibus, S. (2012). Teoria avançada da contabilidade. São Paulo: Atlas, 2.

Madeira, G. J., Mendonça, K. F. C., \& Abreu, S. M. (2003). A disciplina teoria da contabilidade nos exames de suficiência e provão. Contabilidade Vista \& Revista, Ed. Especial (14), pp. 103-122.

Marion, J. C. (1997). A Disciplina Teoria da Contabilidade nos Cursos de Graduação-Algumas Considerações. Contabilidade Vista \& Revista, 8(2), pp. 03-08.

Marion, J. C. (2001). O Ensino da Contabilidade. São Paulo, Atlas, 2.

Matsumoto, A. S., \& Parreira, E. M. (2007). Uma pesquisa sobre o Gerenciamento de Resultados Contábeis: causas e consequências. Contabilidade, Gestão e Governança, 10(1), pp. 141-157.

Miranda, C. D. S., Moraes, M. B. D. C., \& Nakao, S. H. (2008). O Ensino da Teoria da Contabilidade: uma avaliação em instituições no Estado de São Paulo. Anais Encontro da Associação Nacional de Pós-graduação e Pesquisa em Administração, Rio de Janeiro, RJ, Brasil, 32.

Murcia, F., Rover, S., Souza, F. C. D., \& Borba, J. A. (2008). Paradigma atual da ciência contábil: como os docentes de universidades norte-americanas "enxergam a realidade" da pesquisa em contabilidade. In Anais Congresso Associação Nacional dos Programas de Pós-graduação em Ciências Contábeis ANPCONT, II, p. 1-16.

Murcia, F., Rover, S., Souza, F. C. D., \& Borba, J. A. (2008). Paradigma atual da ciência contábil: como os docentes de universidades norte-americanas "enxergam a realidade" da pesquisa em contabilidade. Anais Congresso Associação Nacional dos Programas de Pós-graduação em Ciências Contábeis ANPCONT, Salvador, Bahia, Brasil, 2, p. 1-16.

Nardi, P. C. C., \& Nakao, S. H. (2009). Gerenciamento de resultados e a relação com o custo da dívida das empresas brasileiras abertas. Revista Contabilidade \& Finanças, 20(51), pp. 77-100. http://dx.doi. org/10.1590/S1519-70772009000300006

Nascimento, A. M., \& Bianchi, M. (2005). Um estudo sobre o papel da controladoria no processo de redução de conflitos de agência e de governança corporativa. In Anais Congresso USP de Controladoria e Contabilidade, São Paulo, SP, Brasil, 5.

Nossa, V. (1999). Ensino da Contabilidade no Brasil: Uma análise crítica da formação do corpo docente. São Paulo. Dissertação de Mestrado. Faculdade de Economia e Administração - USP, São Paulo, SP, Brasil.

Pereira, A. G., Bruni, A. L., Rocha, J. D., Lima Filho, R. N., \& Faria, J. A. D. (2010). Teoria dos contratos, governança corporativa e auditoria: delineamentos para a discussão em teoria da contabilidade. Anais do Simpósio de Excelência em Gestão e Tecnologia, Resende, Rio de Janeiro, Brasil, 7.

Piccoli, M. R., Chiarello, T. C., \& Klann, R. C. (2015). A percepção dos acadêmicos sobre conceitos abordados na disciplina de Teoria da Contabilidade. Revista de Gestão, Finanças e Contabilidade, 5(1), pp. 40-57.

Pinheiro, F. A. (1997). O Postulado do Usuário: incentivo ao desenvolvimento da Teoria da Contabilidade e do Contabilista. Caderno de Estudos FIPECAFI, 9(16), pp. 59-65. http://dx.doi.org/10.1590/ S1413-92511997000300004

Ribeiro, H. C. M. (2013). Revista de contabilidade e organizações: Uma análise bibliométrica e de rede social de 2007 a 2012. Revista Iberoamericana de Contabilidad de Gestion - RIGC, 11(22), pp. 1-18.

Ribeiro, H. C. M. (2014). Revista universo contábil: Uma análise do perfil da produção científica sob a ótica da bibliometria e da rede social de 2005 a 2012. Revista Ambiente Contábil, 6(2), pp. 261-281.

Ribeiro, M. De S., \& Lisboa, L. P. (1999). Balanço social. Revista Brasileira de Contabilidade, 115, pp. 1-22. 
Rodrigues, A. (2007). Gerenciamento dos resultados contábeis através de receitas e Despesas não-operacionais: estudo empírico das companhias "Nível 1"- Bovespa. Sociedade, Contabilidade e Gestão, 2(1), pp. 5-18.

Santos, A. D., \& Grateron, I. R. G. (2003). Contabilidade criativa e responsabilidade dos auditores. Revista Contabilidade \& Finanças, 14(32), pp. 7-22. http://dx.doi.org/10.1590/S1519-70772003000200001

Santos, R. D. (2003). "Jogos de empresas" aplicados ao processo de ensino e aprendizagem de contabilidade. Revista Contabilidade \& Finanças, 14(31), pp. 78-95. http://dx.doi.org/10.1590/S151970772003000100006

Triviños, A. N. S. (1987). Introdução à pesquisa em ciências sociais: a pesquisa qualitativa em educação. São Paulo, Atlas.

Vasconcellos, M. L. M. C. (1994). O profissional liberal na docência de 3 grau: uma proposta de atualização pedagógica. Dissertação de Mestrado. Universidade Mackenzie, São Paulo, SP, Brasil. 